LAWRENCE LIVERMORE N A TIO N A L LABORATORY
Plutonium in Peruvian Soil
Project Report

R. W. Williams, V. D. Genetti

March 14, 2008 
This document was prepared as an account of work sponsored by an agency of the United States government. Neither the United States government nor Lawrence Livermore National Security, LLC, nor any of their employees makes any warranty, expressed or implied, or assumes any legal liability or responsibility for the accuracy, completeness, or usefulness of any information, apparatus, product, or process disclosed, or represents that its use would not infringe privately owned rights. Reference herein to any specific commercial product, process, or service by trade name, trademark, manufacturer, or otherwise does not necessarily constitute or imply its endorsement, recommendation, or favoring by the United States government or Lawrence Livermore National Security, LLC. The views and opinions of authors expressed herein do not necessarily state or reflect those of the United States government or Lawrence Livermore National Security, LLC, and shall not be used for advertising or product endorsement purposes.

This work performed under the auspices of the U.S. Department of Energy by Lawrence Livermore National Laboratory under Contract DE-AC52-07NA27344. 


\title{
Pu in Peruvian Soil Project Report
}

\author{
Ross Williams and Victoria Genetti, Chemical Sciences Division, LLNL
}

\begin{abstract}
The ${ }^{239} \mathrm{Pu}$ concentration of the NIST Peruvian soil is less than 1 femtogram per gram $(\mathrm{fg} / \mathrm{g})$. The greatest ${ }^{239} \mathrm{Pu}$ concentration measured using the ${ }^{242} \mathrm{Pu}$ isotope dilution tracer supplied by NIST was $0.93 \mathrm{fg} / \mathrm{g}$ and the minimum was $0.04 \mathrm{fg} / \mathrm{g}$. The simple mean of six spiked analyses is $0.50 \mathrm{fg} / \mathrm{g}$ and the error-weighted mean is $0.64 \mathrm{fg} / \mathrm{g}$, but if the results are weighted by the spike recovery then the ${ }^{239} \mathrm{Pu}$ concentration is $0.37 \mathrm{fg} / \mathrm{g}$. These results for ${ }^{239} \mathrm{Pu}$ are not corrected for analytical blank. A spiked reagent and processing blank gave the equivalent of $0.47 \mathrm{fg} / \mathrm{g}$ when calculated on the basis of a 5 gram sample. If this blank is subtracted from the three 5 gram samples that were analyzed, then none of these three results are distinguishable from zero. If the blank is scaled appropriately and subtracted from the three 10 gram samples, then none of the ${ }^{239} \mathrm{Pu}$ concentrations are greater than $0.7 \mathrm{fg} / \mathrm{g}$. The upper limit of $1 \mathrm{fg} / \mathrm{g}$ for ${ }^{239} \mathrm{Pu}$ is conservative. An isobar at mass 240 of highly variable intensity interfered with the analysis of ${ }^{240} \mathrm{Pu}$, and no reliable results for ${ }^{240} \mathrm{Pu} /{ }^{239} \mathrm{Pu}$ were obtained.
\end{abstract}

\section{Introduction}

An upper limit on the ${ }^{239} \mathrm{Pu}$ concentration in NIST Peruvian Soil 4355A is the only information that can be extracted from the analyses made at LLNL. Due to various difficulties, only 14 of the 25 analyses requested for the experimental protocol were completed. These analyses were one spike-only, six spiked samples and seven un-spiked samples. Although it appears that a signal from ${ }^{239} \mathrm{Pu}$ was detected above background levels for the 6 spiked analyses, the net signal at mass 239 was negative for two of the un-spiked samples. While the net signal at mass 240 was positive for all samples, it was anomalously and unrealistically high relative to mass 239 in 12 of the 13 samples measured, indicating an isobaric interference.

The plutonium isotopic analyses were made with an IsoProbe multi-collector ICP-MS. While the sensitivity of the IsoProbe is very good, the instrument detection limits for the actinides are limited by on-mass background peaks of complex and poorly understood origin. For these analyses, the sensitivity for Pu was approximately $30 \mathrm{cps} / \mathrm{ppq}$ (ppq being femtogram/gram of solution) and the aspiration rate was $60 \mu \mathrm{L} / \mathrm{min}$, which is a total efficiency of slightly more than $1 \%$. All of the plutonium analyses reported here have been corrected for instrumental background as measured on a sample of the acid used to dilute the samples for analysis. 


\section{Results}

The analyses reported here were made by peak hopping 239-240-242 on the axial Daly pulse-counting detector. Although the IsoProbe has the capability of simultaneous multicollection in pulse-counting mode using continuous dynode multipliers, the backgrounds on these multipliers are higher than on the Daly detector, and using a single detector avoids the problem of cross calibrating the different pulse-counting detectors. Data was collected in thirty cycles of 5 second integrations or for a total of 150 seconds at each mass. Data reduction for these samples was done by summing the entire signal at each mass as total counts in 150 seconds. Backgrounds were measured on blank acid using the same data collection methodology as for the samples, and these "blank counts" were subtracted from the sample counts. Poisson counting statistics were used to calculate the 2-sigma uncertainties on the net counts at each mass, and these uncertainties were used in the combined uncertainties $\left(\mathrm{u}_{\mathrm{c}}\right)$ reported in Table 2. The uncertainties are not "total" combined uncertainties, because, for one thing, no corrections for instrumental mass bias have been applied to these data. The magnitude of the multiplicative correction factor for ${ }^{240} \mathrm{Pu} /{ }^{239} \mathrm{Pu}$ is generally about $0.995(0.5 \%)$, and the uncertainty propagated from this correction is less than $1 \%$. This mass bias correction and the uncertainty associated with it are both trivial relative to the magnitude of the uncertainties from counting statistics.

Table 1. Measured ${ }^{240} \mathrm{Pu} /{ }^{239} \mathrm{Pu}$

\begin{tabular}{|c|c|c|c|c|c|}
\hline \multirow{2}{*}{$\begin{array}{l}\text { Experiment } \\
\text { Run number }\end{array}$} & \multicolumn{2}{|c|}{ NIST Peruvian Soil 4355A } & \multirow{2}{*}{$\begin{array}{l}{ }^{242} \text { Pu spike } \\
\text { Added (g) }\end{array}$} & \multicolumn{2}{|c|}{${ }^{240} \mathrm{Pu} /{ }^{239} \mathrm{Pu}$} \\
\hline & Bottle number & grams & & Value & Uncert., $2 \sigma$ \\
\hline 0 & $\mathrm{~N} / \mathrm{A}$ & 0 & 0.7133 & 1.138 & 0.225 \\
\hline 2 & 1609 & 10.0098 & 1.1012 & 0.910 & 0.083 \\
\hline 3 & 1609 & 10 & 0 & 1.380 & 0.121 \\
\hline 4 & 8 & 5.0024 & 0.7158 & 5.052 & 0.947 \\
\hline 5 & 1609 & 5.0229 & 0.7158 & 29.264 & 48.881 \\
\hline 8 & 8 & 5 & 0 & 0.311 & 0.023 \\
\hline 12 & 1333 & 5.0018 & 0.7158 & 2.498 & 0.251 \\
\hline 14 & 1333 & 5 & 0 & $<0$ & 4.400 \\
\hline 16 & 8 & 10 & 0 & 1.532 & 0.206 \\
\hline 17 & 8 & 10.0013 & 1.1012 & 1.852 & 0.287 \\
\hline 20 & 8 & 5 & 0 & 2.795 & 0.452 \\
\hline 22 & 1333 & 5 & 0 & 2.406 & 0.287 \\
\hline 23 & 1609 & 5 & 0 & $<0$ & 0.591 \\
\hline 24 & 1333 & 9.9945 & 1.1002 & 0.966 & 0.171 \\
\hline
\end{tabular}

Two quality control solutions were prepared from NBL certified Pu standards and were analyzed as unknowns with each batch the Peruvian soil samples. The CRM 137 solution was about $24.5 \mathrm{fg} \mathrm{Pu} / \mathrm{mL}$ with ${ }^{240} \mathrm{Pu} /{ }^{239} \mathrm{Pu}$ of 0.2409 , and the CRM 138 solution was about $9.4 \mathrm{fg} \mathrm{Pu} / \mathrm{mL}$ with ${ }^{240} \mathrm{Pu} /{ }^{239} \mathrm{Pu}$ of 0.0862 . The analyses of these solutions are shown in Figure 1 with the lines representing the certified isotopic compositions of the standards. The variations in net counts show the variation in instrumental sensitivity during on different days. All of the CRM $137{ }^{240} \mathrm{Pu} /{ }^{239} \mathrm{Pu}$ analyses lie within their uncertainty $(2 \sigma$, from counting statistics) of the certified value. The analyses of CRM 
138 are more variable, as is expected due to the lower counts, with two having lower ${ }^{240} \mathrm{Pu} /{ }^{239} \mathrm{Pu}$ values than certified.

The ${ }^{240} \mathrm{Pu}$ and ${ }^{239} \mathrm{Pu}$ net counts that combined give the ratios in Table 1 are shown graphically in Figure 2. The anomalously high ${ }^{240} \mathrm{Pu} /{ }^{239} \mathrm{Pu}$ ratios are most likely the result of anomalously high net ${ }^{240} \mathrm{Pu}$ counts, but no more is known about this isobaric interference at mass 240 at the present time.

Figure 1. Analyses of ultra-low level QC standards analyzed with the Peruvian Soils

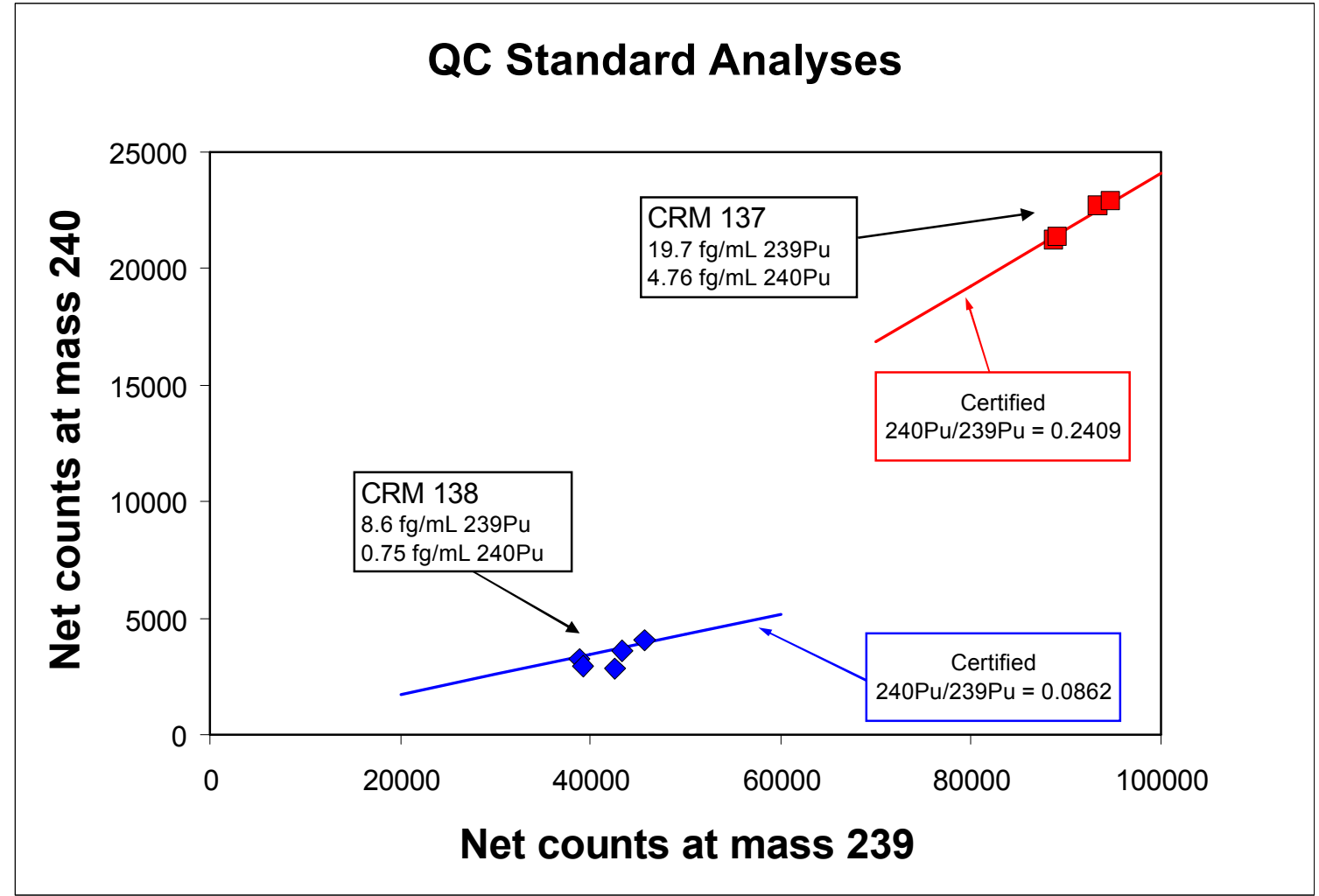


Figure 2. Analyses of the Peruvian Soil samples shown with the QC analyses

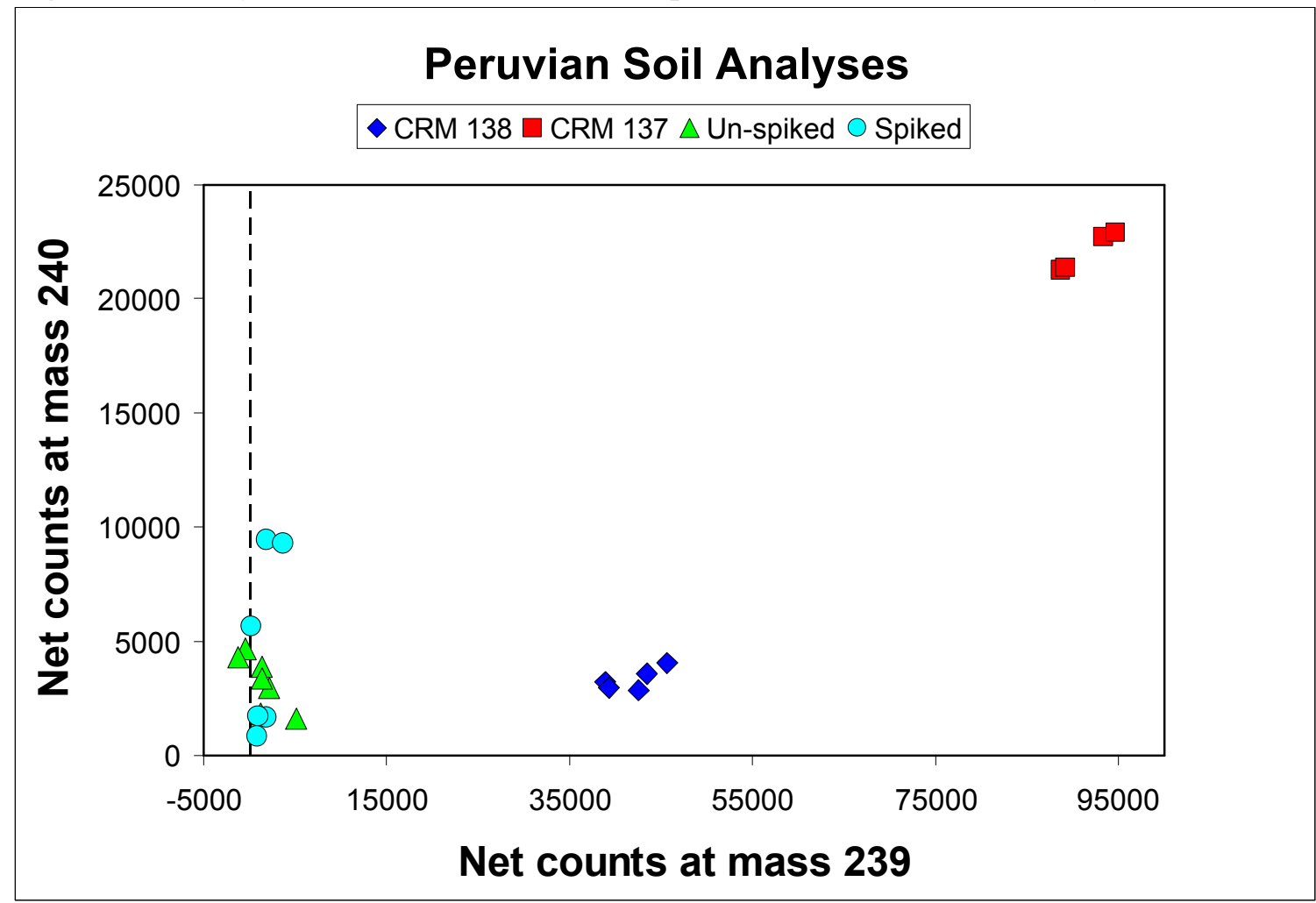

While the variation of the signal at mass 240 for the Peruvian soils is problematic, the signal at mass 242 for the spiked samples is much greater than the background level and greater than that for all the un-spiked samples. Although an isobaric interference may be present at either mass 239 or mass 242, it is reasonable to assume that the 239/242 ratios for the spiked samples represent the maximum possible ${ }^{239} \mathrm{Pu} /{ }^{242} \mathrm{Pu}$ ratios for these samples. The ${ }^{239} \mathrm{Pu}$ concentrations in $\mathrm{fg} / \mathrm{g}$ for these samples are given in Table 2 .

Table 2. ${ }^{239} \mathrm{Pu}$ Concentration Measurements in Peruvian Soil

\begin{tabular}{|c|c|r|r|r|c|}
\hline \multirow{2}{*}{$\begin{array}{c}\text { Experiment } \\
\text { Run number }\end{array}$} & \multicolumn{2}{|c|}{ NIST Peruvian Soil 4355A } & \multicolumn{2}{c|}{${ }^{239}$ Pu femtogram / gram } & ${ }^{242}$ Pu Spike \\
\cline { 2 - 5 } & Bottle number & grams & Value & $\mathrm{u}_{\mathrm{c}}, \mathrm{k}=2$ & Recovery (\%) \\
\hline 2 & 1609 & 10.0098 & 0.928 & 0.069 & 6.3 \\
\hline 4 & 8 & 5.0024 & 0.313 & 0.058 & 35.9 \\
\hline 5 & 1609 & 5.0229 & 0.040 & 0.066 & 29.3 \\
\hline 12 & 1333 & 5.0018 & 0.520 & 0.050 & 43.0 \\
\hline 17 & 8 & 10.0013 & 0.813 & 0.116 & 3.7 \\
\hline 24 & 1333 & 9.9945 & 0.384 & 0.056 & 7.5 \\
\hline
\end{tabular}

As requested, the samples were dried at 40 degrees $\mathrm{C}$ for 24 hours prior to weighing. For nine samples treated in this way the weight loss was $0.08 \pm 0.02 \%$.

The ${ }^{242} \mathrm{Pu}$ spike recoveries for the 5 gram samples were significantly better than those for the 10 gram samples. Considerable time and effort were put into understanding the problem and revising the analytical method to overcome it, but the resources for this 
project were expended before the final test samples were analyzed. The only results available are those in Tables 1 and 2.

Perhaps it is significant that the ${ }^{239} \mathrm{Pu}$ concentrations are, on average, lower for the 5 gram samples with better recoveries than for the 10 gram samples. However, there is no reason to exclude the 10 gram samples when evaluating the ${ }^{239} \mathrm{Pu}$ content. Considered together, these six sample analyses give an upper limit of 1 femtogram per gram for the ${ }^{239} \mathrm{Pu}$ concentration of the Peruvian Soil 4355A. Further treatments of these data are summarized in the abstract, and the ${ }^{239} \mathrm{Pu}$ concentrations in atoms/gram are given in the following table.

Table 3. ${ }^{239} \mathrm{Pu}$ concentrations in atoms $/ \mathrm{g}$

\begin{tabular}{|c|c|r|r|r|r|}
\hline \multirow{2}{*}{$\begin{array}{c}\text { Experiment } \\
\text { Run number }\end{array}$} & \multicolumn{2}{|c|}{ NIST Peruvian Soil 4355A } & \multicolumn{2}{c|}{${ }^{239}$ Pu atoms / gram } & ${ }^{242}$ Pu Spike \\
\cline { 2 - 5 } & Bottle number & grams & Value & $\mathrm{u}_{\mathrm{c}}, \mathrm{k}=2$ & Recovery (\%) \\
\hline 2 & 1609 & 10.0098 & $2.34 \mathrm{E}+06$ & $1.75 \mathrm{E}+05$ & 6.3 \\
\hline 4 & 8 & 5.0024 & $7.88 \mathrm{E}+05$ & $1.46 \mathrm{E}+05$ & 35.9 \\
\hline 5 & 1609 & 5.0229 & $9.99 \mathrm{E}+04$ & $1.67 \mathrm{E}+05$ & 29.3 \\
\hline 12 & 1333 & 5.0018 & $1.31 \mathrm{E}+06$ & $1.25 \mathrm{E}+05$ & 43.0 \\
\hline 17 & 8 & 10.0013 & $2.05 \mathrm{E}+06$ & $2.93 \mathrm{E}+05$ & 3.7 \\
\hline 24 & 1333 & 9.9945 & $9.66 \mathrm{E}+05$ & $1.42 \mathrm{E}+05$ & 7.5 \\
\hline
\end{tabular}

